\title{
Using a multidisciplinary approach with undergraduate students to study the grass endophyte system
}

\author{
T.L. BULTMAN ${ }^{1}$, TJ SULLIVAN ${ }^{1}$, D. SWARTHOUT ${ }^{1}$, \\ K. BROWN ${ }^{2}$ and T. PENNINGS ${ }^{3}$ \\ ${ }^{1}$ Department of Biology; ${ }^{2}$ Department of Chemistry, ${ }^{3}$ Department of Mathematics, Hope College, Holland, MI USA
} bultmant@hope.edu

\begin{abstract}
We have been collaborating on a multidisciplinary research programme with undergraduate (baccalaureate) students for the past 3 years, funded by the National Science Foundation in the USA. The project focuses on the ecological interaction between endophytic fungi and the grasses they inhabit and involves students (10-15 annually) and faculty (5 and 1 post-doc) from the departments of Biology, Chemistry and Mathematics. We briefly present some of our results from ongoing projects on stomatal conductance and photosynthetic rates in tall fescue, wound-induced responses at the molecular level, and modelling tri-trophic level interactions. We also discuss how we came together to initiate the project; challenges, pitfalls, and advantages of doing multidisciplinary, multi-investigator research with undergraduates. We will present our assessment results, which are focused on how students feel their involvement in multidisciplinary research differs from what it would be in disciplinary research.
\end{abstract}

Keywords: Neotyphodium coenophialum, tall fescue, woundinduced response, tri-trophic interactions, water use efficicency, stomatal conductance, photosynthesis

\section{Introduction}

Hope College is a distinguished four-year, liberal arts, undergraduate institution known for excellence in science and mathematics. Hope's current enrollment is 3,035 undergraduate students. The institution was recently recognised as one of the top four institutions nationally in undergraduate research by US News and World Report.

The mission of the programme in science and mathematics at Hope mirrors that of the college to provide an innovative curriculum, which intertwines student learning and faculty development. Faculty realise that science, particularly biology, is becoming increasingly multidisciplinary and have actively embraced a recent initiative within the division to infuse the introductory curriculum with interdisciplinary modules.

The authors have been conducting a multidisciplinary project that focuses on endophytic fungi and provides multidisciplinary research experiences to undergraduate students. Fungal endophytes, common symbionts of grasses, can be of fundamental ecological importance as mediators of induced resistance (Bultman et al. 2004) and greater drought tolerance (West 1994) by their hosts, and as modulators of trophic dynamics in grassland systems (Omacini et al. 2001). We are testing for these effects across a spectrum of grass/endophyte associations and thereby aim to address gaps in our understanding of the ecological roles these fungi play in natural and applied ecosystems. Specifically, we test for the generality of induced and constitutive resistance and their molecular basis. We also seek to understand how water use efficiency differs between E- and E + tall fescue. Finally, we are attempting to determine how endophytes affect plant fitness within a multitrophic level context through building theoretical models and empirically testing them with laboratory experiments.

\section{Methods}

Tests for wound-induced resistance mediated by fungal endophyte

Lolium arundinacea ("Kentucky-31") seeds, both with (E+) and without (E-) Neotyphodium coenophialum (provided by $\mathrm{H}$. Fribourg, University of Tennessee) were planted individually in $10 \mathrm{~cm}$ pots containing Sunshine LC1 mix (Sun Gro Horticulture). Plants in the infected treatment group were verified for infection using immunoblotting. Plants were fertilised weekly with Peter's liquid fertilizer (20-20-20 N-P-K) at a rate of 300 ppm of nitrogen. Twenty-five individuals from both $\mathrm{E}+$ and $\mathrm{E}$ - treatments were used in each damage treatment. The three damage treatments were: cutting all shoot tissue $3 \mathrm{~cm}$ above the soil (hereafter referred to as cut), damage by the invertebrate herbivore Spodoptera frugiperda (herbivore) and no damage (control). The treatments were applied 6 weeks after germination. To test for increased defenses on subsequent herbivores, Rhopalosiphum padi was used as the herbivore bioassay as in Bultman et al. (2004). A parallel experiment was performed with Glyceria striata (provided by C. Schardl, Univ. of Kentucky) infected with Epichloe glyceriae, except that only E+ plants were used.

Table $1 \mathrm{~N}$ acetyl-norloline in individual plants of Glyceria striata infected with Epichloe glyceriae. Results are expressed as area under the HPLC peaks.

\begin{tabular}{lcc}
\hline Treatment & Rep & N-Acetyl norloline \\
\hline Control & 1 & 0 \\
& 2 & 0 \\
& 3 & 0 \\
& 4 & 28654 \\
& 5 & 0 \\
Herbivory & 6 & 0 \\
& 7 & 0 \\
& 1 & 0 \\
& 2 & 0 \\
Cut & 3 & 0 \\
& 4 & 0 \\
& 5 & 0 \\
& 1 & 856407 \\
& 2 & 18283 \\
& 3 & 40746 \\
& 4 & 23400 \\
& 5 & 17085 \\
\hline
\end{tabular}


Figure 1 Interaction between $N$. coenophialum-infection in tall fescue and host damage. Letters above columns indicate significant differences as determined by Tukey's HSD. Cut = previously cut with scissors. Herb = previously damaged by fall armyworm.

\section{D $\mathrm{CD}$}

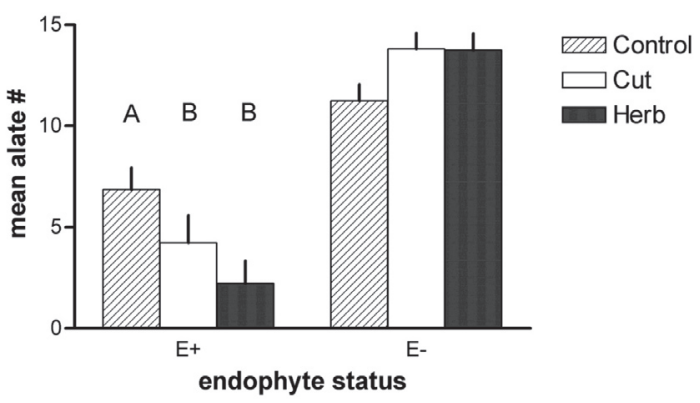

Tissue samples of leaf blades were taken 2 weeks after damage for chemical analysis. Statistical analysis was performed using JMP IN 5.1 (SAS Institute 2003). The number of living $R$. padi was analysed using 2-way ANOVA with the presence of $N$. coenophialum and damage type as factors. The number of living aphids was $\log +1$ transformed to normalise the data.

\section{Water use efficiency}

Water-use efficiency (WUE) and stomatal conductance were studied in L. arundinacea (Kentucky-31 variety) plants that were infected with the fungal endophyte, Neotyphodium coenophialum, and plants that were uninfected. We monitored how tightly WUE was regulated during the dehydration of $\mathrm{E}+$ and $\mathrm{E}$ - plants in two experiments in 2005 (summer and fall). Plants were cut $3 \mathrm{~cm}$ above the soil at 6 weeks after which two water treatments were implemented. High water plants were maintained at $1000 \mathrm{~g}$ (saturated mass) $3 \mathrm{x}$ weekly after cutting. Low water plants were maintained at $800 \mathrm{~g} 3 \mathrm{x}$ during the first week after cutting. During the remaining 2 weeks of the experiment, supplemental water was withheld from the low water pots except for the application of $100 \mathrm{~mL}$ of $300 \mathrm{ppm}$ of Peters solution (20:20:20 NPK) fertiliser to all the pots once a week.

Gas exchange measurements were taken on 8-day, 15-day and 21-day on newly developed leaf blades. Measurements were taken on three fully expanded leaf blades $7 \mathrm{~cm}$ from the leaf sheath using a Li-Cor 6400 (Lincoln, NE, USA) infrared gas analyzer (IRGA). Rates of photosynthesis, stomatal conductance, transpiration internal leaf $\mathrm{CO}_{2}$ concentrations $\left(\mathrm{p}_{\mathrm{i}}\right)$ and wateruse efficiency were measured after the leaf stabilised under the cuvette conditions after 2-3 minutes.

The average of each gas exchange variable for the three leaf blades from each pot was used for the analyses. Simple linear regressions were performed on physiological variables that were thought to be interdependent. In the case where significant regressions between two physiological variables were found, an Analysis of Covariance was performed to investigate whether E+ and E- physiological responses were different. Not all treatments had five replicate samples in them after eliminating $\mathrm{E}+$ plants that tested negative for the presence of the endophyte at the end of the experiment. In the summer experiment $20 \%$ of the E+ was not infected, whereas $30 \%$ of E+ plants were not infected in the fall experiment.
Figure 2 Apterous $R$. padi on Glyceria striata plants. Control = not previously damaged. Cut $=$ previously damaged with scissors. Herbivory = previously damaged by fall armyworm. Error bars = 1 SEM. Histograms with common letters are not significantly different $\left(\mathrm{F}_{2,65}=4.26, \mathrm{P}<0.05\right)$

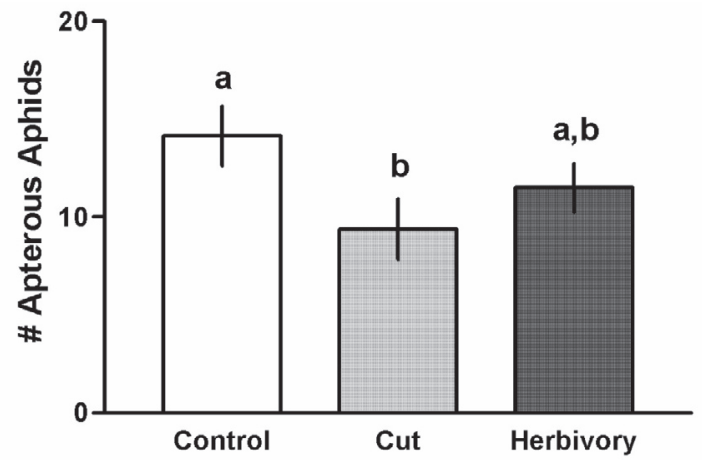

Modeling tri-trophic interactions

Three differential equations were constructed; one for tall fescue, one for fall armyworm and one for Euplectrus parasitoid populations. Empirically-collected data were collected on various parameters of the models in laboratory experiments.

\section{Management and assessment of the multidisciplinary research programme}

Initiation and continuation of the programme required regular communication among the investigators. To foster student understanding of the overall goals of the project an orientation meeting occurred the first week of the summer in which students and faculty discussed pertinent literature and an overview of the project was presented by the principal investigator. During the first 4 weeks, students participated in lab rotations/workshops in which students explained methodologies used in their lab. All students made informal presentations of their proposed work to the entire biology department (12 faculty and 35 students) 2 weeks into the summer experience. They also made formal presentations at the end of the summer and were required to present their results in an off-campus venue.

To evaluate students' perception of their experience in this multidisciplinary project relative to a discipline-specific experience, a questionnaire was distributed to students at the end of the summer.

\section{Results and Discussion}

\section{Tests for wound-induced resistance mediated by} fungal endophyte

The presence of $N$. coenophialum had a negative effect on final $R$. padi number $\left(\mathrm{F}_{1,144}=144.9, \mathrm{P}<0.0001\right.$; Fig. 1). There was also a significant interaction between the presence of $N$. coenophialum and damage $\left(\mathrm{F}_{2,144}=3.29, \mathrm{P}<0.05\right)$. Damaged Eplants showed increased susceptibility to $R$. padi while damaged $\mathrm{E}+$ demonstrated increased resistance (Fig. 1).

Glyceria striata also exhibited a wound-induced response (Fig. 2). Rhopalosiphum padi numbers were reduced on plants that had been previously damaged by cutting, but not on those that had been damaged by fall armyworm. The presence of $\mathrm{N}$ acetyl norloline was associated with the cut plants, but not with those that had been damaged by fall armyworm or had not been damaged (controls) (Table 1). No other loline derivatives were 
Figure 3 Stomatal conductance versus pot mass for $\mathrm{E}+$ (open circles) and E- plants (filled circles) grown under high (a) and low (b) water treatments in summer and fall 2005. Data are means for three leaf blades per pot at each sampling period that occurred in the summer and fall experiments. (a) $\mathrm{E}+$ stomatal conductance $=0.793$ pot mass - 143.2, $\mathrm{P}<0.001$; E- stomatal conductance $=0.873$ pot mass $-133.9, \mathrm{P}<0.001$. (b) $\mathrm{E}+$ stomatal conductance $=$ 1.274 pot mass $-352.6, \mathrm{P}<0.001$; E- stomatal conductance $=2.016$ pot mass $-551.9, \mathrm{P}<0.001$.
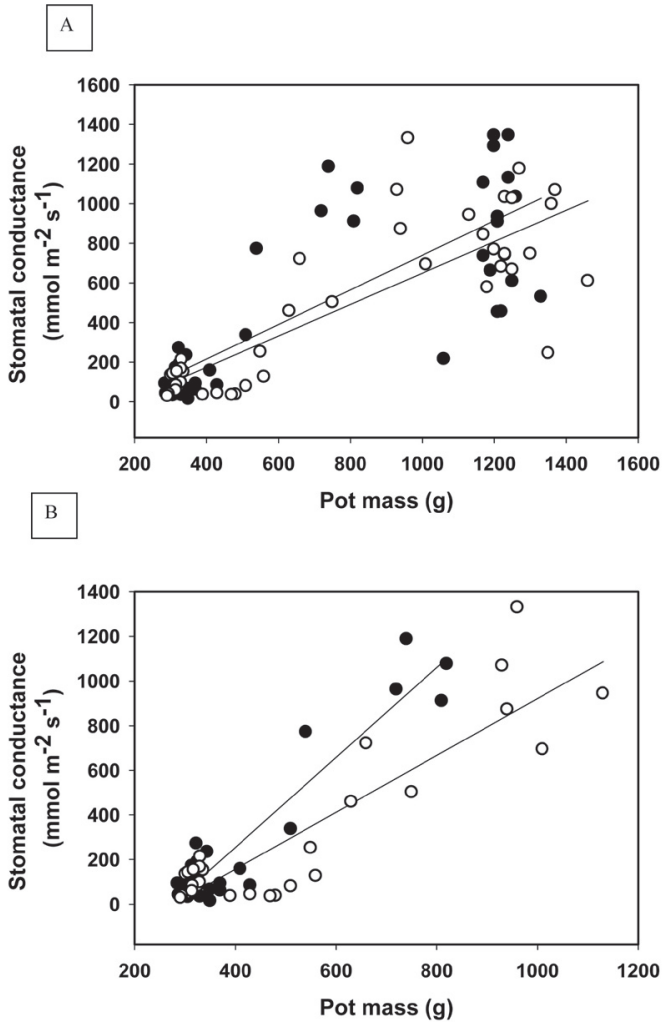

detected. We conclude that wound-inducible resistance is typical in tall fescue (see also Bultman et al. 2004) and that it appears early in the evolutionary history of grass endophytes; even a type I infection, like that in G. striata, can exhibit an inducible resistance with upregulation of bioprotective chemicals (and presumably genes as well).

\section{Water use efficiency}

Stomatal conductance declined with pot mass in both E+ and E- plants in the high water treatment, but the relative slopes of responses in stomatal conductance to varying pot mass were the same for $\mathrm{E}+$ and $\mathrm{E}$ - plants when combining data from both summer and fall experiments $\left(\mathrm{F}_{1,86}=2.528, \mathrm{P}>0.05\right)$ (Fig. 3a). Overall, there was no difference in stomatal conductance between $\mathrm{E}+$ and $\mathrm{E}$ - grasses as stress was imposed over the two successive 3 week experimental periods ( 981 to 54 and 982 to $47 \mathrm{mmol}$ $\mathrm{m}^{-2} \mathrm{~s}^{-1}$, respectively). However, there was a difference between $\mathrm{E}+$ and E- plants in stomatal conductance at similar pot masses over time in the low water treatment (Fig. 3b). As soil moisture content declined, stomatal conductance declined more rapidly in
Figure 4 WUE versus stomatal conductance for $E_{+}$ and E- plants grown under high (a) and low (b) water treatments in summer and fall of 2005. Symbols are the same as figure 1. Data are means of three leaf blades per pot at each sampling period that occurred in summer and fall experiments. (a) $E+$ WUE $=5.3-0.0014$ stomatal conductance, $\mathrm{P}>0.05 ; \mathrm{E}-\mathrm{WUE}=5.3$ stomatal conductance -0.0016 stomatal conductance, $P<0.05$. (b) $E+W U E=6.0$ - 0.0166 stomatal conductance, $\mathrm{P}>0.05$; $\mathrm{E}-\mathrm{WUE}=0.051$ stomatal conductance $-1.7, \mathrm{P}<0.001$.
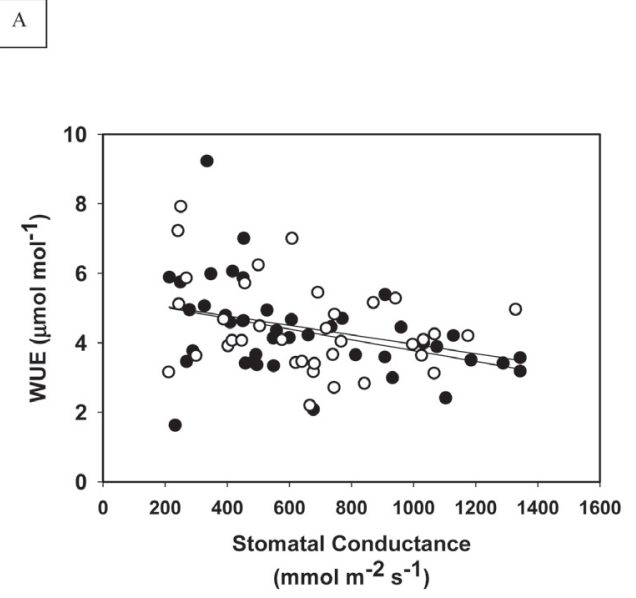

B

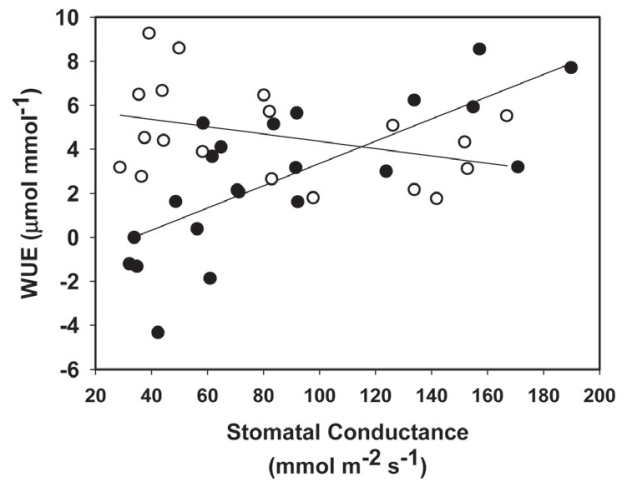

E- plants compared to in E+ plants (Test for differences in the slopes of the regression lines: $\mathrm{F}_{1,56}=5.996, \mathrm{P}<0.05$ ). In addition, for pot masses between $1200 \mathrm{~g}$ and $500 \mathrm{~g}$, E+ plants had lower stomatal conductance than E- plants (Fig. 3b).

WUE did not change in a significant manner in summer and fall experiments when stomatal conductances varied from 1400 $\mathrm{mmol}$ and $200 \mathrm{~m}^{-2} \mathrm{~s}^{-1}$ in $\mathrm{E}+$ plants (Fig. $4 \mathrm{a}, \mathrm{r}=0.307, \mathrm{n}=36$, $\mathrm{P}>0.05$ ), whereas WUE increased as stomatal conductances declined in this range for $\mathrm{E}$ - plants $(\mathrm{r}=0.381, \mathrm{n}=43, \mathrm{P}<0.05)$. Slopes of the regression lines for $\mathrm{E}+$ and $\mathrm{E}-$ plants did not differ $\left(\mathrm{F}_{1,75}=0.69, \mathrm{P}>0.05\right)$. As stomatal conductances declined from 200 to below $100 \mathrm{mmol} \mathrm{m}^{-2} \mathrm{~s}^{-1}$, E+ grasses maintained a relatively constant WUE relative to when stomatal conductances were above $200 \mathrm{mmol} \mathrm{m}^{-2} \mathrm{~s}^{-1}$ (Fig. 4b, $\mathrm{r}=0.364, \mathrm{n}=19, \mathrm{P}>0.05$ ). In contrast, E- plants showed a significant decline in WUE when 
stomatal conductance ranged from 200 to less than $100 \mathrm{mmol} \mathrm{m}^{-2}$ $\mathrm{s}^{-1}$ (Fig. 4b, $\mathrm{r}=0.732, \mathrm{n}=22, \mathrm{P}<0.001$ ). The different responses in WUE to a decline in stomatal conductance in $\mathrm{E}+$ and $\mathrm{E}$ - plants are shown by the significantly different slopes in the regression lines (Figure 4b, $\mathrm{F}_{1.37}=4.76, \mathrm{P}<0.05$ )

We conclude that $\mathrm{E}+$ plants maintained a constant WUE across a wide range in stomatal conductance and that the endophyte clearly maintains this constancy under drought conditions while plants without the fungus do not. The data suggest that drought tolerance may be associated with the maintenance of constant water-use efficiency in compliance with the optimisation theory proposed by Cowan and Farquhar (1977) and tested in a series of experiments by Wong et al. (1985a,b,c).

\section{Modeling tri-trophic interactions}

The equation for grass growth in biomass we developed is:

$$
\frac{d G}{d t}=a G\left(1-\frac{G}{k}\right)-b H \frac{G}{d+G}
$$

Where, $G$ stands for the biomass of the grass, a is the growth constant of the grass, $H$ is the fall armyworm population density, $b$ is the conversion of the grass into fall armyworm, $k$ is the carrying capacity for the grass and $d$ is the satiation constant.

The equation for fall armyworm population growth we developed is:

\section{$\frac{d H}{d t}=i H \frac{G}{d+G}-m P H-q H$}

Where $H$ is the density of the fall armyworm, $i$ is the growth constant for the fall armyworm population, $m$ is the conversion of herbivores into parasitoids, $P$ is the density of parasitoids, and $q$ is the death rate of unparasitised fall armyworm.

The equation for the parasitoid (Euplectrus comstockii) population growth we developed is:

$$
\frac{d P}{d t}=r P H-s P
$$

Where $r$ is the growth constant of the parasitoid population and $\mathrm{s}$ is the death rate of the parasitoid population.

Parameters of each model are being quantified (with and without $N$. coenophialum) so that they can be input into the models and an analysis of the stability of the tritrophic interaction can be undertaken.

Initiation, management and assessment of the multidisciplinary programme involving undergraduate students.

The primary hurdle in initiating the project was convincing coinvestigators to take on a project that was tangential to their current ongoing work. The opportunity for significant extramural funding to each investigator provided a convincing argument. Communication has been essential and not always optimal due to the busy lives of academic scientists. It is the perception of the investigators that the weekly scheduled events for faculty and students have been very helpful in building a sense of community in the group. Students responded that they were grateful for the opportunity to participate in multidisciplinary research and found communication with students from other majors the most challenging aspect of the programme.

\section{REFERENCES}

Bultman, T.L.; Bell, G; Martin, W. 2004. A fungal endophyte mediates reversal of wound-induced resistance and constrains tolerance in a grass. Ecology 85: 679-685.

Cowan, I.R.; Farquhar, G.D. 1977. Stomatal function in relation to leaf metabolism and environment. Symposium for the Society of Experimental Biology 31: 471-505.

Fronhoffs, S., Totzke, G; Stier, S; Wernert, N; Rothe, M; Bruning, T; Koch, B; Sachinidis, A; Vetter, H; Ko, Y. 2002. A method for the rapid construction of cRNA standard curves in quantitative real-time reverse transcription polymerase chain reaction. Molecular and Cellular Probes 16: 99-110.

Omacini, M.; Chaneton, E.J.; Ghersa, C.M.; Muller, C.B. 2001. Symbiotic fungal endophytes control insect host-parasite interaction webs. Nature 409: 78-81.

SAS Institute, I. 2003. JMP IN. SAS Institute, Cary, North Carolina, USA.

Siegel, M.R.; Latch, G.C.M.; Bush, L.P.; Fannin, F.F.; Rowan, D.D.; Tapper, B.A.; Bacon, C.W.; Johnson, M.C.. 1990. Fungal endophyte-infected grasses: alkaloid accumulation and aphid response. Journal of Chemical Ecology 16: 3301-3315.

Spiering, M.J.; Moon, C.D.; Wilkinson, H.H; Schardl, C.L. 2005. Gene clusters for insecticidal loline alkaloids in the grass-endophytic fungus Neotyphodium uncinatum. Genetics 169: 1403-1414.

West, C.P. 1994. Physiology and drought tolerance of endophyteinfected grasses. pp. 87-99 In: Biotechnology of Endophytic Fungi of Grasses. Eds. Bacon, C.W.; White, J.F., Jr.; CRC Press, Boca Raton, FL, USA.

Wong S.C.; Cowan I.R.; Farquhar G.D. 1985a. Leaf conductance in relation to rate of $\mathrm{CO}_{2}$ assimilation. I. Influence of nitrogen nutrition, phosphorus nutrition, photon flux density, and ambient partial pressure of $\mathrm{CO}_{2}$ during ontogeny. Plant Physiology 78: 821-825.

Wong S.C.; Cowan I.R.; Farquhar G.D. 1985b. Leaf conductance in relation to rate of $\mathrm{CO}_{2}$ assimilation. II. Effects of short-term exposures to different photon flux densities. Plant Physiology 78: 826-829.

Wong S.C.; Cowan I.R.; Farquhar G.D. 1985c. Leaf conductance in relation to rate of $\mathrm{CO}_{2}$ assimilation. III. Effects of water stress and photoinhibition. densities. Plant Physiology 78: 830-834. 